\title{
Bisphosphonates in the treatment of HIV-related osteoporosis
}

\author{
Fabio Vescini • Franco Grimaldi
}

Received: 20 October 2014/ Accepted: 19 November 2014/Published online: 26 November 2014

(c) Springer Science+Business Media New York 2014

In this number, Pepe et al. are publishing a paper evaluating the effects of 1 year of risedronate treatment on bone mineral density (BMD) in HIV-infected patients with or without hypogonadism [1]. Their results show that also, risedronate is effective in the therapeutic management of osteoporosis in HIV, as well as alendronate and zoledronate.

Subclinical vertebral fractures are common in HIVinfected persons with a prevalence that can be as high as $25 \%$ and they should be considered a strong risk factor for future fractures [2, 3].

Anti-osteoporosis treatment should be initiated for HIVinfected patients on the basis of the same criteria as those used in general population [4, 5]. Therefore, all HIVinfected postmenopausal women and the seropositive men aged more than 50 years, at high risk for fracture, should be offered a therapy. However, as a matter of fact, many of these patients are young females and males and, as for the general population, a treatment threshold has yet to be established for HIV patients younger than 40 years. A more prudent approach must be followed in young HIV patients, but an anti-osteoporosis therapy should be considered in response to a fragility fracture [5].

Many drugs are available for the treatment of osteoporosis and their efficacy has always been established on the basis of their ability in reducing fracture risk. On the contrary, no trials have been done on the anti-fracture effects of these drugs in HIV. The ability of bisphosphonates in increasing BMD has been demonstrated in HIVpositive patients, while no data are available on the use of bone-forming agents (teriparatide and PTH 1-84).

F. Vescini $(\varangle) \cdot$ F. Grimaldi

Endocrinology and Metabolism Unit, University-Hospital

S. Maria della Misericordia, Udine, Italy

e-mail: vescini.fabio@aoud.sanita.fvg.it
One of the first studies on this matter showed that 1-year administration of oral alendronate weekly was able to decrease bone turnover markers by more than $50 \%$, thus reproducing the data obtained in seronegative patients [6]. In the meantime, another paper demonstrated that a 2-year treatment with alendronate induced a significant increment of BMD in HIV-infected patients compared to placebo [7]. The data were confirmed a couple of years later when McComsey et al. published the results of a randomized, placebo-controlled, double-blinded phase II trial comparing alendronate and placebo in osteopenic $\mathrm{HIV}+$ patients; interestingly, a high rate of men were enrolled in this study (71\%), confirming other data on the efficacy of alendronate in males [8].

One of the biggest inconveniences perceived both by HIV patients and by their doctors is the pills burden. Even though many efforts have been done in order to reduce the number of daily pills, the addition of a drug like alendronate can be felt as a problem. On the contrary, a yearly injection appears to be very appealing solution. This accounts for the early development of studies with annual intravenous injection of zoledronate that have demonstrated that this schedule can produce a significantly higher increase of BMD than placebo [9]. Zoledronic acid is usually given $5 \mathrm{mg}$ intravenous yearly. Less frequent dosing schedules (e.g., every 2 years or every 5 years) have been shown to equally suppress bone turnover and preserve BMD, but the anti-fracture efficacy of these alternative dosing strategies has not been established in any population [10].

Chronic vitamin D deficiency is very frequent in HIVinfected subject [11]. As vitamin D deficiency can blunt bone response to bisphosphonate treatment, cholecalciferol should always be administered before initiating a therapy with an anti-resorptive drug [12]. 
Treatment duration should be individualized as in the general population. Bisphosphonate treatment should be reviewed after an initial 3-5 years period, both because of concerns about the negative effects of long-term suppression of bone turnover (such as osteonecrosis of the jaws (ONJ) and atypical femoral fractures) and because ONJ seems to be more frequently associated with immune deficiency [13-15]. Moreover, ONJ is more frequent in people with diabetes, in steroid-treated patients, and in smokers [15]. As a matter of fact, these last conditions are somehow more frequent in HIV-infected patients than in the general population, therefore a more cautious approach to bisphosphonates treatment should be followed.

Even though no data are available on fracture incidence reduction, alendronate or zoledronate or risedronate must be considered to enhance BMD and possibly decrease fracture incidence in HIV-infected patients at high risk for fragility fractures.

\section{References}

1. J. Pepe, A.M. Isidori, M. Falciano, G. Iaiani, A. Salotti, D. Diacinti, R. Del Fiacco, E. Sbardella, C. Cipriani, S. Piemonte, O. Raimo, P. Biondi, F. Biamonte, A. Lenzi, S. Minisola, Effect of risedronate in osteoporotic HIV males, according to gonadal status: a pilot study. Endocrine (2014). doi:10.1007/s12020-0140349-0

2. M. Borderi, L. Calza, V. Colangeli, E. Vanino, P. Viale, D. Gibellini, M.C. Re, Prevalence of subclinical vertebral fractures in HIV-infected patients. New Microbiol. 37, 25-32 (2014)

3. C. Torti, G. Mazziotti, P.A. Soldini, E. Focà, R. Maroldi, D. Gotti, G. Carosi, A. Giustina, High prevalence of radiological vertebral fractures in HIV-infected males. Endocrine 41, 512-517 (2012)

4. J.D. Lundgren, M. Battegay, G. Behrens, S. De Wit, G. Guaraldi, C. Katlama, E. Martinez, D. Nair, W.G. Powderly, P. Reiss, J. Sutinen, A. Vigano, EACS Executive Committee, European AIDS Clinical Society (EACS) guidelines on the prevention and management of metabolic diseases in HIV. HIV Med. 9(2), 72-81 (2008)

5. G.A. McComsey, P. Tebas, E. Shane, M.T. Yin, E.T. Overton, J.S. Huang, G.M. Aldrovandi, S.W. Cardoso, J.L. Santana, T.T. Brown, Bone disease in HIV infection: a practical review and recommendations for HIV care providers. Clin. Infect. Dis. 51(8), 937-946 (2010)
6. G. Guaraldi, G. Orlando, G. Madeddu, F. Vescini, P. Ventura, S. Campostrini, M.S. Mura, N. Parise, R. Caudarella, R. Esposito, Alendronate reduces bone resorption in $\mathrm{HIV}$-associated osteopenia/osteoporosis. HIV Clin. Trials 5(5), 269-277 (2004)

7. K. Mondy, W.G. Powderly, S.A. Claxton, K.H. Yarasheski, M. Royal, J.S. Stoneman, M.E. Hoffmann, P. Tebas, Alendronate, vitamin $\mathrm{D}$, and calcium for the treatment of osteopenia/osteoporosis associated with HIV infection. J. Acquir. Immune. Defic. Syndr. 38(4), 426-431 (2005)

8. G.A. McComsey, M.A. Kendall, P. Tebas, S. Swindells, E. Hogg, B. Alston-Smith, C. Suckow, G. Gopalakrishnan, C. Benson, D.A. Wohl, Alendronate with calcium and vitamin D supplementation is safe and effective for the treatment of decreased bone mineral density in HIV. AIDS 21(18), 2473-2482 (2007)

9. M.J. Bolland, A.B. Grey, A.M. Horne, S.E. Briggs, M.G. Thomas, R.B. Ellis-Pegler, A.F. Woodhouse, G.D. Gamble, I.R. Reid, Annual zoledronate increases bone density in highly active antiretroviral therapy-treated human immunodeficiency virusinfected men: a randomized controlled trial. J. Clin. Endocrinol. Metab. 92(4), 1283-1288 (2007)

10. M.J. Bolland, A. Grey, A.M. Horne, S.E. Briggs, M.G. Thomas, R.B. Ellis-Pegler, G.D. Gamble, I.R. Reid, Effects of intravenous zoledronate on bone turnover and bone density persist for at least five years in HIV-infected men. J. Clin. Endocrinol. Metab. 97(6), 1922-1928 (2012)

11. F. Vescini, A. Cozzi-Lepri, M. Borderi, M.C. Re, F. Maggiolo, A. De Luca, G. Cassola, V. Vullo, G. Carosi, A. Antinori, V. Tozzi, A.D. Monforte, Icona Foundation Study Group, Prevalence of hypovitaminosis D and factors associated with vitamin D deficiency and morbidity among HIV-infected patients enrolled in a large Italian cohort. J. Acquir. Immune. Defic. Syndr. 58, 163-172 (2011)

12. S. Adami, S. Giannini, G. Bianchi, L. Sinigaglia, O. Di Munno, C.E. Fiore, S. Minisola, M. Rossini, Vitamin D status and response to treatment in post-menopausal osteoporosis. Osteoporos. Int. 20, 239-244 (2009)

13. M.L. Gourlay, J.P. Fine, J.S. Preisser, R.C. May, C. Li, L.Y. Lui, D.F. Ransohoff, J.A. Cauley, K.E. Ensrud, Study of Osteoporotic Fractures Research Group, Bone-density testing interval and transition to osteoporosis in older women. N. Engl. J. Med. 366, 225-233 (2012)

14. National Osteoporosis Guideline Group. Osteoporosis: Clinical guideline for prevention and treatment. www.shef.ac.uk/NOGG/ May (2013)

15. G. Campisi, L.L. Russo, A. Agrillo, P. Vescovi, V. Fusco, A. Bedogni, BRONJ expert panel recommendation of the Italian Societies for Maxillofacial Surgery (SICMF) and Oral Pathology and Medicine (SIPMO) on Bisphosphonate-Related Osteonecrosis of the Jaws: risk assessment, preventive strategies and dental management. Ital. J. Maxillofac. Surg. 22(2), 103-124 (2011) 